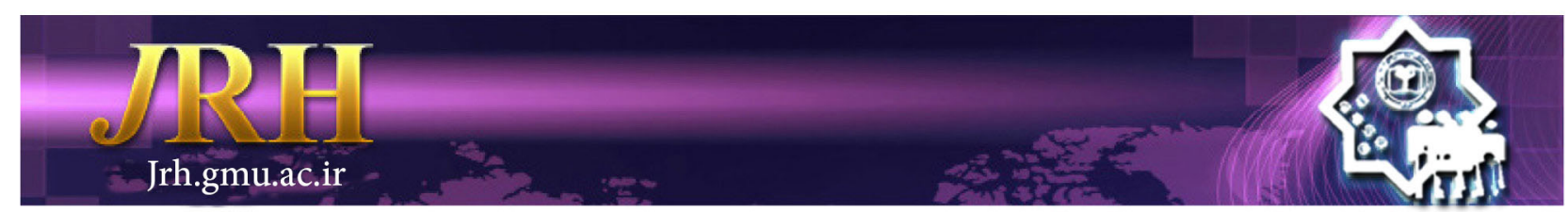

\title{
Applying activity-based costing to determine the final costs of radiology services in Shiraz, Iran: a concurrent equations approach
}

Hossein Khoshnoud Khankahdani ${ }^{1}$

\author{
Journal of Research \& Health \\ Social Development \& Health Promotion \\ Research Center \\ Vol. 9, No.4, Jul \& Agu 2019 \\ Pages: $309-314$ \\ DOI: 10.29252 /jrh.9.4.309 \\ Original Article
}

1. Correspondence to: Department of Accounting, School of Accounting and Management, Payame Noor University, Khavaran, Iran

Email: Mehdi313@mailfa.com

Received: 7 Jun 2014

Accepted: 6 Mar 2016

How to cite this article: Khoshnoud Khankahdani H. Applying activity-based costing to determine the final costs of radiology services in Shiraz, Iran: a concurrent equations approach. $J$ Research \& Health2019; 9(4): 309- 314.

\begin{abstract}
The Activity-Based Costing (ABC) method possesses the capability to identify the costs accurately and provide non-financial information for improving system function and increasing its efficiency. The present study aimed to calculate the final costs of radiology services to determine the final costs deviation from the enacted tariffs. This study was a retrospective cross-sectional analysis of radiology final costs for 19 different types of radiology services (1077 stereotypes) at the hospital in Shiraz, Iran. The required data was collected through reports, specified forms, interviewing with hospital personnel and authorities as well as direct observation of hospital activity centers. The final costs of the radiology services were determined using the activity-based costing method as well as the cost sharing of activity centers through concurrent equations technique. The results showed a great amount of loss for all provided services in this center. The Mean tariff of the services equaled 625,626 Rials while the mean final cost of the provided services equaled 3,036,390 Rials. So, the findings of this study show an average loss of 2,410,764 Rials for each service.
\end{abstract}

Keywords: Cost Allocations, Cost-Benefit Analysis, Cost Sharing, Health Care Costs, Hospital Costs, Hospital Radiology Department

\section{Introduction}

Undoubtedly, all the people have has the right to be healthy and this fact has been inevitably accepted by everyone, especially health policymakers [1]. However, providing health services regardless of their predicted final costs has raised the challenging question of whether it is possible to provide services with less resources in the world today [2]. Besides, a shortage of information resources, reliance on governmental budget, as well as lack of transparency in the actual amount of service expanses lead to inefficiency and waste of resources [3]. To adapt efficient and effective decisions, managers need an accurate and real-time amount of the expanses in hospitals. This information which are considered as the output of accounting systems in hospitals are of great importance in calculating the final costs of the provided services [4].

Currently, the final costs of health services is calculated by fixed tariffing in most countries such as Iranwhile it is not an appropriate method because it does neither provide enough information for health decisionmakers nor present the final costs of the services accurately. Therefore, it is essential 
to design a system which compensate the pitfalls of the present method. During past decades, the costing methods such as activitybased costing have developed a lot. Activitybased costing method is used in hospitals for several reasons including its advantages over the tariffing method in calculating the final costs of the services, its ability to identify the idle resources and capacities in the hospital and adopting appropriate approaches for optimal of the existing resources [5]. Furthermore, activity-based costing system provides more useful information on service provision, support activities and the service/product costs which help the managers to increase the profit by focusing on pivotal services and processes [6]. The activity-based costing method which is one of the costing systems for products was presented by Caplan and Johnson for the first time. This method is not a substitution for job costing or process costing methods, but it can be applied along with them [7].

\section{Method}

This study was a cross-sectional research conducted in the radiology department of Ordibehesht hospital, Shiraz, Iran. In the current study, he final costs of 19 types of provided services in the form of 1077 radiology stereotype, were calculated using the activitybased costing method and compared to the approved governmental tariffs. Data was collected through the expanse tables and forms, studying the related documents, as well as observation and interviews. Overall, this study was designed and conducted as the following:

A) Identifying the hospital activity centers (the hospital wards in where an activity is performed) and categorizing them based on the kind of their activity into; 1) operational centers; 2) supporting/administrative centers; and 3) diagnostic centers.

1) Operational centers: These centers are directly involved in providing healthcare services to patients, like surgery, neurology and heart units.

2) Supporting/administrative centers: These centers are not directly involved in providing healthcare services to patients but perform public services to support the activities of operational and diagnostic centers, like accounting or security units.

3) Diagnostic centers: These centers are responsible for providing diagnostic services, like laboratory or radiology department.

B) Next, using the existing documents and reports, the expenses of each supporting/ administrative center (including the costs of human resources, materials, depreciation and overhead costs) were calculated separately.

C) Then, given that the supportive centers are used for costing operations in the activitybased costing system, the costs of each supportive center had to be identified and allocated to the service-receiving units. In fact, the expenditures of each supportive center consisted of two main parts; the direct costs of that activity center as well as the costs which are allocated from other activity centers. Therefore, the costs of each center were calculated according to the following formula:

The costs of each activity center= the share of this center out of the costs of other centers + the related costs of each center (directly or indirectly)

Where, $\mathrm{b}$ is the direct costs of each activity center and $\sum_{j=1}^{n} \%(\mathrm{Xi})$ is the allocated costs from other activity centers to this center. To allocate the costs, at first the activity centers were defined in the form of a matrix in which the percentages (calculated based on the allocation basics of each activity center) of services, either provided or received by each center, were included by vertical and horizontal. After that, the above-mentioned equation was repeated for all support centers of the hospital. Each equation, includes a constant variable (the cost of the activity centers which was calculated at the stage B) and several algebraic variables (the percentages of the support centers services to this activity center). For example, in order to calculate the costs of the management activity center using the concurrent equations we had: The costs of management activity center $=\mathrm{Z}+$ 
the cost of security center $(n \%)+$ the cost of computer center $(\mathrm{n} \%)+\ldots .$.

Accordingly, such an equation was repeated for all supportive centers. Given that solving such an equation with too many algebraic variables was difficult, time-consuming and confusable MATLAB Software was used to calculate the final costs of the activity centers using the concurrent equations approach.

D) First, the final costs of each activity center were allocated to the costing centers using the concurrent equations approach and considering the matrix of provided services percentage using Excel Software.

E) Then, the final costs were determined based on each output. To do so, after specifying the final costs of activity centers or the centers with outputs, the final cost for each output was calculated by dividing the total allocated costs to each activity center by the number of defined outputs for each activity center.

\section{Results}

In Table 1, the final costs of radiology services for each stereotype in the Ordibehesht Hospital are presented. The final costs of the services included the consuming materials costs (film + film cover $)+$ annual salary and bonus + the maintenance and repair cost of equipments + building accumulated depreciation + equipment depreciation + share of hospital information system (HIS) costs + physicians per case + energy (water, electricity, gas and telephone) costs + the allocated costs from other units.

The final costs of radiology services, as well as the governmental tariffs of the provided services are presented in Table 2. According to this results, not only all the provided services had no profit but also created losses of which the maximum was related to cervical spine radiography $(20,516,501$ Rials $)$ and the minimum was related to brain CT Scan (1,198,927 Rials).

\section{Discussion}

The findings of the present study showed that the final costs of provided services in the radiology department were consisted of the following components:

The equipment depreciation $(53.233 \%)$; the allocated costs from other uints (15.475\%); annual salary and bonus (14.320\%); maintenance and repair costs (7.085\%); physicians per case $(4.096 \%)$; buildings depreciation (3.657\%); energy costs (1.599\%); the unit share of HIS costs $(0.345 \%)$; and the consuming materials costs $(0.189 \%)$

However, the findings of Javan Bakht et al revealed that the personnel costs $(55.7 \%$ of unit total costs) had the highest share of the expanses, while the costs of consuming materials accounted for $7.57 \%$ and energy (water, electricity, telephone and gas) for $0.32 \%$ of the total unit costs. Their results also showed that the unit depreciation costs $(208,824,509$ Rials) formed $14.96 \%$ of the unit total costs [8].

Lievens et al. showed that the best possible way for calculating the real costs of radiotherapy services is using the activity-based costing approach [9]. In 1997, West. T.D. and West. D.A. examined the efficiency of the activitybased costing system in the dialysis unit. The findings of their study which showed a significant difference between the final costs calculated by the activity-based costing system and that of the traditional approach, would be important in management decision-makings [10]. Cohen at al found that academic staffs spent $72 \%$ of their time on clinical activities. In addition, they found that radiology image reading had the highest costs in clinical expanses (almost 23\% of the total costs) [11]. Olukoga showed that personnel cost which was the major expanse was accounted for $73 \%$ to $82 \%$ of the unit costs [12]. Demeere et al. also attempted to analyze and examine the relevance and managerial impacts of timedriven activity-based costing on five separate units of an outpatient clinic. Their results suggested that the final costs of the provided services was significantly different from the governmental tariffs [13].

Moreover, according to Torabi et al, the actual costs to each radiography service was as follows: human resources $(43.3 \%)$, the 


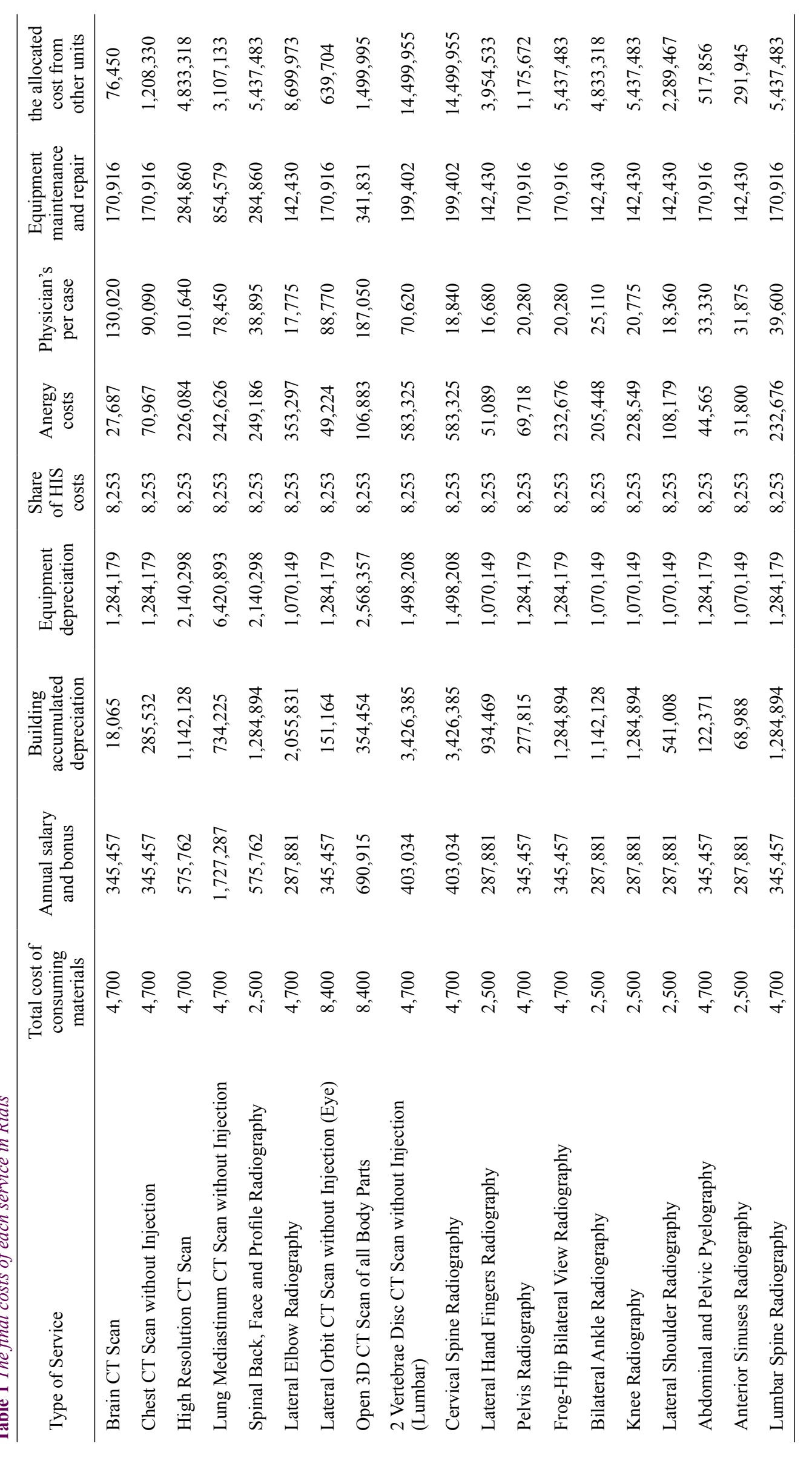


Table 2 Comparison of the final services cost of radiology department with governmental tariffs in 2012.

\begin{tabular}{lccc}
\hline Type of service & $\begin{array}{c}\text { The final cost of the } \\
\text { service }\end{array}$ & $\begin{array}{c}\text { Governmental tariff } \\
\text { Train CT scan }\end{array}$ & $\begin{array}{c}\text { Total deviation for } \\
\text { each service }\end{array}$ \\
\hline Chest CT scan without injection & $3,065,727$ & 866,800 & $-1,198,927$ \\
High resolution CT scan & $9,317,044$ & 600,600 & $-2,867,823$ \\
Lung mediastinum CT scan without injection & $13,178,147$ & 677,600 & $-8,639,444$ \\
Spinal back, face and profile radiography & $10,022,131$ & 523,000 & $-12,655,147$ \\
Lateral elbow radiography & $12,640,288$ & 259,300 & $-9,762,831$ \\
Lateral orbit CT scan without injection (Eye) & $2,746,067$ & 118,500 & $-12,521,788$ \\
Open 3D CT scan of all body parts & $5,766,139$ & 591,800 & $-2,154,267$ \\
2 Vertebrae disc CT scan without injection & $20,693,881$ & $1,247,000$ & $-4,519,139$ \\
(Lumbar) & $20,642,101$ & 470,800 & $-20,223,081$ \\
Cervical spine radiography & $6,467,984$ & 125,600 & $-20,516,501$ \\
Lateral hand fingers radiography & $3,356,990$ & 111,200 & $-6,356,784$ \\
Pelvis radiography & $8,788,839$ & 135,200 & $-3,221,790$ \\
Frog-hip bilateral view radiography & $7,717,217$ & 135,200 & $-8,653,639$ \\
Bilateral ankle radiography & $8,482,914$ & 167,400 & $-7,549,817$ \\
Knee radiography & $4,468,226$ & 138,500 & $-8,344,414$ \\
Lateral shoulder radiography & $2,531,627$ & 122,400 & $-4,345,826$ \\
Abdominal and pelvic pyelography & $1,935,821$ & 222,200 & $-2,309,427$ \\
Anterior sinuses radiography & $8,808,159$ & 212,500 & $-1,723,321$ \\
Lumbar spine radiography & & 264,000 & $-8,544,159$ \\
\hline
\end{tabular}

allocated costs from other units $(30.5 \%)$, the specialized consuming materials (12.1\%), specialized equipment depreciation $(9 \%)$, building depreciation $(3 \%)$, office equipment depreciation $(0.5 \%)$, energy costs $(0.8 \%)$ and general consuming materials $(0.3 \%)$. In their study, the highest and the lowest costs were allocated to human resources $(2,510,287,740$ Rials) and general consuming materials $(20,211,884$ Rials) with the amount of and [14]. Nik Pajooh et al also indicated that the personnel costs of radiology department $(1,788,100,000$ Rials) had occupied the largest share of the operating expanses (66.19\%) and unit total costs $(62 \%)$ Other costs consisted of consuming materials and repair/maintenance (16.61\%), equipment depreciation of radiology unit (6.34\%), energy and general costs (9.72\%). Besides, the share of this unit from other support centers was $9.72 \%$ [15].

Mousavi et al reported the final costs for most of selected outputs in radiology centers more than those of governmental tariffs. Besides, the highest and lowest deviations from the tariffs of 2008 in the radiology department were related to bilateral view arm radiography $(45,469$ Rials) and bilateral lumbosacral radiography (2,052 Rials) [16].

In addition, Ghiasvand et al. (2013) found the highest level of deviation as a loss in front chest radiography (31,496 Rials) for Alavi Hospital and in upper GI radiography (129,685 Rials) for Imam Khomeini Hospital [17].

\section{Conclusion}

Due to low activity of radiology department (providing 3 services per day), it was assumed to bring loss instead of benefit. The findings of the current study support this assumption, as well. Some causes of this loss might be as follows: the low activity of this center, high transmission costs from other centers as well as the accumulated depreciation costs of the equipments.

It is worth mentioning that 1077 stereotypes had been provided over a year in the radiology department of Ordibehesht Hospital, Shiraz, Iran. The total income of these services were equal to $673,799,400$ Rials and their final costs were equal to $3,249,387,355$ Rials. Hence, it 
is revealed that this center loss has been equal to $2,575,587,955$ Rials over the course of one year.

\section{Acknowledgments}

The author wish to thank all the managers of ordibehesth Hospital to support data collection and review.

\section{Authors' contributions}

Study design: HKH

Data Collection and Analysis: $\mathrm{HKH}$

Manuscript preparation: HKH

All authors have read and approved the final version

\section{Conflict of Interest}

"The authors declared that they have no competing interests."

\section{Funding}

The author (s) received no financial support for the research, authorship and/or publication of this article.

\section{Availability of data and materials}

The datasets used and/or analyzed during this study are available from the corresponding author on reasonable request.

\section{References}

1- Ahmadi Jahanabad F, Moshrefzade KH, Davari K, Parisaei Z, Dayanati KH, Abravan J. Cost-analysis in health \& medication services in health sector of Kohgiluyeh \& Boyrahmad province. Armaghene Danesh2005; 10(3): 85-93.

2- Bakhtiyari P. Accounting and financial management for managers. Tehran: Industrial management organization publication; 2013.

3- Ebadi Fard Azar F, Gorji A, Esmaili R. Calculation and unit cost analysis of health care services delivered in Shahriar S.A.Bakhshi health center by activity based costing 2006. Journal of Health Administration2006; 9(23): 31-40.

4- Hadian M, Mohammadzadeh A, Imani A, Golestani "step-down method" in Fatemieh hospital of Semnan university of medical sciences-2006 Iran. Journal of Health Administration2009; 12(37): 39-48.

5- Rajabi A. Basics of design and application of Activity Based Costing (ABC) based on the cost of hospital services. Shiraz: Shiraz Navid publication; 2008.

6- Cooper R, Kaplan RS. Profit priorities from activitybased costing. Harv Bus Rev1991; 63(3) 130-5.

7- Namazi M. Investigating the activity-based costing system in management accounting and its behavioral considerations. Journal of the Accounting and Auditing Review1999; 7(2): 71-106.

8- Javanbakht M, Mohammadzadeh A, Mashayekhi A, Salavati S. An application of activity based costing system in radiology ward of Hafez hospital. Journal of Medical Council of Iran2013; 31(1): 15-23.

9- Lievens Y, Van Den Bogaert W, Kesteloot K. Activitybased costing: a practical model for cost calculation in radiotherapy. Int $J$ Radiat Oncol Biol Phys2003; 57(2): 522-35.

10- West TD, West DA. Applying ABC to healthcare. Management Accounting1997; 78(8): 22-33.

11- Chohen M, Hawsed D, Hutchins GD, McPhee WD, LaMasters MB, Fallon RP. Activity based cost analysis: A method of analyzing the financial and operating performance of academic radiology departments. Radiology2000; 215(3): 708-16.

12- Olukoga A. Unit costs of inpatient days in district hospitals in South Africa. Singapore Med J2007; 48(2): 143-7.

13- Demeere N, Stouthuysen, K, Filip R. Timedriven activity based costing in an outpatient clinic environment: development, relevance and managerial impact. Health Policy2009; 92(2-3): 296-304.

14- Torabi A, Keshavarz Kh, Najafpour Z, Mohamadi E. Computing cost price by using activity based costing (abc) method in radiology ward of Golestan hospital in Ahvaz university of medical sciences in 2009. Hospital2011; 10(2): 38-49.

15- Nik Pajho A, Shariati B, Soheyli S. Estimation of unit cost of radiology services in Amir Aalam hospital. Payesh2009; 8(3): 235-44.

16- Mousavi SA, Khorvash F, Fathi H, Fadai H. Survey the average of cost in outpatient and imaging in alzahra hospital and comparing with service's tariff. Health Information Management2010; 7(2): 235-41.

17- Ghiyasvan H, Zandiyan H, Zahirian Moghadam T, Naghdi S. Cost of radiology services using the activity based costing (ABC) method. Payesh2013; 12(6): 595-605.

\section{Analysis and unit cost estimation of services using}

